\title{
Twin Weddings; Twin Research Summaries; Twin Events; Professor Phil S. Holzman
}

\author{
Nancy L. Segal \\ Department of Psychology, California State University, United States of America
}

\begin{abstract}
P eople are intensely interested in factors underlying earning power and what can be done to enhance it. A recent study using monozygotic male twins adds to knowledge in this area. Based on data from 136 twin pairs, the investigators favored a correlational hypothesis, namely that simply being married raises salaries by 19 to $26 \%$. Following a review of this research, summaries of twin studies presented at the biennial meeting of the International Society for Human Ethology in Ghent, Belgium (July 27-30, 2004) and at the annual meeting of the Human Behavior and Evolution Society in Berlin, Germany (July 21-25, 2004) are presented. The final section of this article provides information of general interest to twin researchers, physicians and others working in twin-related fields.
\end{abstract}

\section{Twin Weddings and Wages}

There has been widespread interest in factors underlying individual differences in ability to earn wages (Segal, 2000). A series of studies combining twin research and economics have tried to provide answers. A creative research study that addressed these questions was recently completed by Kate Antonovics in the Department of Economics at the University of California, San Diego, and Robert Town in the School of Public Health at the University of Minnesota.

The researchers began by noting the well-known relationship between marriage and salary: married men earn more money than their unmarried counterparts. However, the connection between these two measures has remained uncertain. Antonovics and Town (2004) tested three alternative hypotheses, the first two of which were causal in nature: (1) Being married increases male productivity because it gives individuals more time to engage in profes- sional work-related activities, and (2) Employers favor married men. The third hypothesis was selectional: (3) Men who are more productive are more likely to marry.

Twin participants were drawn from the Minnesota Twins Registry (MTR). This resource, maintained at the University of Minnesota, includes approximately $80 \%$ of the 10,400 intact Minnesota twin pairs who were born between 1936 and 1955. In 1994, the twins received a Socioeconomic Survey with questions concerning wages, work hours, educational attainment and other relevant information. Data were available for 280 monozygotic (MZ) twin pairs, although study criteria reduced this number to 136 pairs. Thirty-one of the twin pairs $(23 \%)$ were discordant for marital status. Only male twin pairs were included. The sample appeared representative of the U.S. population with reference to age, wages, work hours, education and other demographic variables that were controlled in the analysis.

Cross-sectional analyses of the data showed that married men earned a $19 \%$ higher wage than unmarried men. This figure increased to $26 \%$ when wage differences within pairs were examined. The investigators' interpretation was that being married causes men's wages to rise.

I learned about this intriguing study in the New York Times (Varian, 2004) and examined the original report for additional details. The study is an excellent step toward clarifying the bases of financial productivity. However, it also raises many questions that deserve answers before the findings can be considered conclusive. First, it would have been informative to have examined personality measures which are available for

Address for correspondence: Nancy L. Segal, Department of Psychology, California State University, Fullerton, CA 92834, USA. E-mail:nsegal@fullerton.edu 
the Minnesota Twin Registry pairs. Specifically, do more dominant twins earn higher wages? Do they marry earlier? Secondly, how similar were the twins' jobs? Did any of the twins work together? A compelling argument for the effects of marriage on earnings might have been made from studying MZ twins who work together, but who differ in marital status.
The New York Times writer left open the possibility that the married twin differed in some fundamental way from his twin brother, such that being married was not a sufficient causal factor in how much money he made. This is an appropriate reservation. Other crucial questions concern MZ female twins: How do the earnings of $M Z$ female twins compare when both are married, when both are single and when only one is married? How does having children affect male and female twins' financial status? Finally, the association between being married and being happy is well-known (see the study by Kohler below). Conceivably, individuals who are happier are likely to be more motivated and productive - this could possibly be one of the unknown factors underlying married male twins' greater earning capacity.

\section{Twin Research Summaries: Belgium to Berlin}

A large number of professional meetings took place throughout Europe this summer. The International Congress of Twin Studies, which met in July 2004 in Odense, Denmark, was the only meeting dedicated exclusively to twin research. However, twin studies were presented at two other meetings: the International Society for Human Ethology in Ghent, Belgium (July 27-30, 2004) and the Human Behavior and Evolution Society in Berlin, Germany (July 21-25, 2004). I attended both of these meetings.

It is gratifying that some members of these societies are using twin designs to test hypotheses generated by evolutionary theorizing. Reasons favoring a closer association between behavioral geneticists and evolutionary psychologists have been put forth by a number of researchers, including Mealey (2001) and Segal and Hill (in press). Both disciplines can gain a great deal from collaboration: evolutionary researchers can take advantage of twin and adoption methods, while behavioral geneticists and twin researchers can give greater consideration to differences in heritability and malleability among behavioral traits.

\section{International Society for Human Ethology}

A twin study of best friends was presented by J. Philippe Rushton (2004) from the University of Western Ontario, in Canada. A sample of 322 pairs of adult twins (174 MZ pairs and 148 dizygotic [DZ] pairs) was identified from the University of London Twin Register. They were asked to complete questionnaires concerning their education, social attitudes and personality. Not surprisingly, the friends of MZ twins were more similar than the friends of DZ twins. Heritability of friendship choice was estimated to be $30 \%$, while unique environmental effects were estimated to be $70 \%$. The shared family environment did not affect choice of friends.

Sexual orientation, fertility and body odour was presented by Mark Sergeant (2004) from Nottingham Trent University, in the United Kingdom. Female olfactory perception is affected by timing of the menstrual cycle. Specifically, female perceptions of androstenone, a substance present in male body odor, are more positive at the time of ovulation. Female raters in this study were asked to provide their preferences to odors from heterosexual and homosexual males; it was suggested that male homosexuality may be maintained by 'providing characteristics beneficial for intersexual contact'. It was found that females preferred the odors of the homosexual males to those of the heterosexual males. Unfortunately, the sample size was quite small - odor samples were available for only 10 homosexual males and 10 heterosexual males. This study did not use twins, but exposing females to the scents of MZ male twins discordant for sexual orientation could possibly confirm the present finding, as well as to help identify the factor(s) responsible for the female preference. This is because using $\mathrm{MZ}$ twins controls for unknown factors that might affect the findings.

\section{Human Behavior and Evolution Society}

Partner + children $=$ happiness? An assessment of the effect of fertility and partnerships on subjective well-being in Danish twins was presented by Hans-Peter Kohler (2004) from the University of Pennsylvania. The title of his talk was generated by theories suggesting that forming social relationships and having children raises happiness. This concept was tested using 25- to 45-year-old and 50- to 70-year-old twins from the 
Danish Twin Registry. It was found that having a partner increased happiness irrespective of having children; having the first child increases happiness; males gain a $75 \%$ increase in happiness if the first-born child is male; having second and later-born children does not affect happiness in males, but does decrease happiness in females; having children at a young age reduces happiness for females, but not for males; having had children does not affect happiness in 50- to 70-year-old male and females.

Fitness indicator theory predicts genetic correlation patterns among intelligence and personality traits in 2,144 pairs of British 7-year-old twins was presented by Geoffrey Miller (2004) from the University of New Mexico. He tested the prediction that if intelligence and kindness evolved as 'good gene indicators' then such traits should show positive correlations, particularly in males. Twin participants included members of the Twins Early Development Study in London. Available data included cognitive tests, parent-rated behaviors and teacher-rated behaviors. Genetic correlations were generally more positive in male children than in female children, as expected.

\section{Twin Events: Twin Sisters, Twin Brothers, Twin Cities and Twin Logos}

\section{Twin Sisters}

The 2004 presidential election in the United States has focused attention on President George Bush's fraternal twin daughters, Jenna and Barbara. The twins attended different colleges and are now pursuing different careers: Jenna has applied to teach at a charter school in Harlem, and Barbara plans to work with AIDSaffected children in Eastern Europe and in Africa (Bumiller, 2004). It is unfortunate that a recent newspaper article compared the physical attractiveness of the two twins, to each other and to Alexandra and Vanessa Kerry, the nontwin daughters of Senator John Kerry, Bush's Democratic opponent (Catton, 2004). This article was unfair and unnecessary. Many of the problems twins and siblings face come from the uninvited comparisons of people who hardly know them.

\section{Twin Brothers}

The loss of a young twin child is a terrible tragedy for many reasons. In late July at the end of the day, children attending the Park Shore Country Day Camp in Long Island, New York were waiting under the trees for buses to arrive to take them home. A 4year-old boy, Justin Michaels, was hit by a falling branch and died shortly thereafter (the tree appeared healthy from the outside, but experts noted that internal decay can occur undetected). I was in New York City at the time and heard this sad story repeated several times on television and on the radio. However, the fact that Justin had a twin brother, Daniel, was never mentioned - I learned this from a newspaper article that appeared several days later (O'Donnell, 2004). Daniel will most likely become a living reminder of the twin brother that he once had. Hopefully, the twins' parents will be put in touch with other bereaved families who will best understand their profound grief.

\section{Twin Cities}

At the close of the 2004 Twin Congress I traveled through Denmark and Norway. In Trondheim, Norway's third largest city, I was given a booklet highlighting local attractions. A section called 'Other Practical Information' listed Trondheim's Twin Towns, fourteen in total. The fourteen towns are: Graz, Austria; Kopavogur, Iceland; Split,
Croatia; Petah-Tikvah, Israel; Odense, Denmark; Kaunas, Lithuania*; Tammerfors, Finland; Tiraspol, Moldavia; Klaksvik, Faeroe Islands*; Dunfermline, Scotland; Upernavik, Greenland*; Norrköping, Sweden; Darmstadt, Germany; and Vallejo, California. (Note: How these fourteen cities were chosen is unclear. * indicates informal appointment.)

\section{Twin Logos}

Copenhagen's stroget is lined with intriguing restaurants and shops. There I discovered 'Zwilling J.A. Henckels', a company manufacturing a vast assortment of kitchen gadgets. I was less intrigued with the products than with the name of the company and the logo: a pair of stick-figure twins. It turns out that the symbol can be traced back to June 1731 - the Gemini sign. At that time, a knife maker named Johann Peter Henckels from Solingen registered with that symbol. The twin logo is now one of the oldest trademarks in the world. The web site shows how the form of the twin logo evolved over the years, changing in $1810,1850,1875$, 1900 and 1969. Additional information about this company is available at www.zwilling.com 


\section{Professor Philip S. Holzman}

Professor of Psychology and Psychiatry, Philip S. Holzman, was memorable for his contributions to our understanding of schizophrenia and for his tremendous warmth and enthusiasm. One of my best graduate courses at the University of Chicago was the 'Psychopathology of the Schizophrenias', taught by Dr. Holzman in the Spring 1974. Several years later Dr. Holzman relocated to Harvard University, after which time I saw him only occasionally at conferences.

I spent May 2004 at Harvard University as part of a sabbatical leave. I contacted Dr. Holzman and spent a wonderful evening with him and with another Chicago friend and colleague, Dr. Deborah L. Levy. Several weeks later, Dr. Holzman was admitted to hospital for what was to be a fairly routine procedure, but he suffered a stroke and passed away several days later. $\mathrm{He}$ was 82 years old.

Dr. Holzman's recent work concerned cognitive impairment in schizophrenia, but he had contributed to research in psychiatric genetics and was excited about progress in twin studies. He com-

\section{References}

Antonovics, K., \& Town, R. (2004). Are all the good men married? Uncovering the sources of the marital wage premium. American Economic Review, 94, 317-321.

Bumiller, E. (2004, July 14). Bush twins leap into limelight. New York Times, p. A18.

Catton, P. (2004, July 30). In Bush vs. Kerry, the brunettes are winning. New York Sun, p. 1.

Kohler, H.-P. (2004, July). Partner + children $=$ happiness? An assessment of the effect of fertility and partnerships on subjective well-being in Danish twins. Paper presented at the meeting of the Human Behavior and Evolution Society, Berlin, Germany. pleted several twin studies with Dr. Einar Kringlen in Norway, and with other investigators. The basic idea was to compare concordance rates for eye-tracking dysfunction (ETD) in twins who were clinically discordant for schizophrenia. It was found that the MZ concordance rate for eye tracking was approximately twice the DZ concordance rate, consistent with the genetic transmission of ETD. Moreover, the presence of ETD in clinically healthy co-twins indicated that it was not a secondary effect of being ill, but rather of having the relevant genes. His 152 publications (listed in PubMed) span the years 1954 to 2004; titles of his twin-related papers are printed below. He will be missed.

\section{Papers by Dr. Philip S. Holzman}

Holzman P. S., Levy, D. L., Matthysse, S. W., \& Abel, L. A. (1997). Smooth pursuit eye tracking in twins. A critical commentary. Archives of General Psychiatry, 54, 429-431.

Holzman, P. S., Kringlen, E., Matthysse, S., Flanagan, S. D., Lipton, R. B., Cramer, G., Levin, S., Lange, K., \& Levy, D. L (1988). A single dominant gene can account for eye tracking dysfunctions and schizophrenia in offspring of discordant twins. Archives of General Psychiatry, 45, 641-647.

Matthysse, S., \& Holzman, P. S. (1988). Comment on Berenbaum, Oltmanns, and Gottesman (1985): 'Formal thought disorder in schizophrenics and their twins'. Journal of Abnormal Psychology, 97, 105-109.

Holzman, P. S., Meltzer, H. Y., Kringlen, E., Levy, D. L., Haberman, S. J., \& Davis, J. M. (1979). Plasma CPK levels in monozygotic and dizygotic twins discordant for schizophrenia. Journal of Psychiatric Research, 15, 127-131.

Holzman, P. S., Kringlen, E., Levy, D. L, Proctor, L. R., \& Haberman, S. (1978). Smooth pursuit eye movements in twins discordant for schizophrenia. Journal of Psychiatric Research, 14, 111-120.

Holzman, P. S., Kringlen, E., Levy, D. L., Proctor, L. R., Haberman, S. J., \& Yasillo, N. J. (1977). Abnormalpursuit eye movements in schizophrenia. Evidence for a genetic indicator. Archives of General Psychiatry, 34, 802-805.
Mealey, L. (2001). Kinship: The tie that binds (disciplines). In H. R. Holcomb III (Ed.), Conceptual challenges in evolutionary psychology: Innovative research strategies (pp.19-38). Dordrecht, The Netherlands: Kluwer.

Miller, G. (2004, July). Fitness indicator theory predicts genetic correlation patterns among intelligence and personality traits in 2,144 pairs of British 7-year-old twins. Paper presented at the meeting of the Human Behavior and Evolution Society, Berlin, Germany.

O’Donnell, M. (2004, August 1). Tree's decay, and bad timing, cause a boy's death. New York Times, p. 29.

Philippe Rushton, J. (2004, July). A twin study of best friends. Paper presented at the meeting of the International
Society for Human Ethology, Ghent, Belgium.

Segal, N. L. (2000). Entwined lives: Twins and what they tell us about human behavior. New York: Plume.

Segal, N. L., \& Hill, E. M. (in press). Developmental behavioral genetics and evolutionary psychology: Tying the theoretical and empirical threads. In B.J. Ellis \& D.F. Bjorkland (Eds.), Origins of the social mind: Evolutionary psychology and child development. New York: Guilford.

Sergeant, M. (2004, July). Sexual orientation, fertility and body odour. Paper presented at the meeting of the International Society for Human Ethology, Ghent, Belgium.

Varian, H.R. (2004, July 29). Economic scene. New York Times, p. C2. 